\title{
Erratum: The surface science of nanocrystals
}

Michael A. Boles, Daishun Ling, Taeghwan Hyeon and Dmitri V. Talapin

Nature Materials 15, 141-153 (2016); published online 22 January 2016; corrected after print 27 January 2016.

In the version of this Review Article originally published, the righthand panel of Fig. $1 \mathrm{~b}$ was incorrect. The correct Figure is shown below and this error has been corrected in the online versions of the Review Article.

a

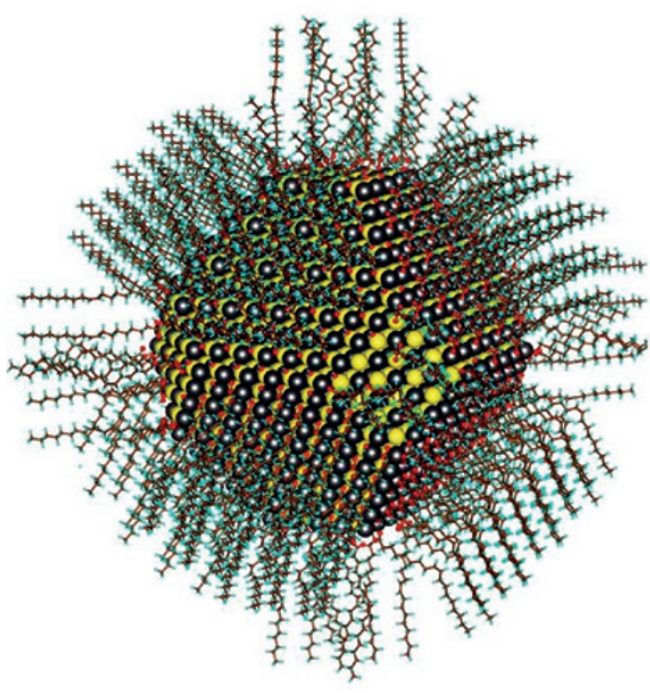

$\mathrm{PbS}$ b

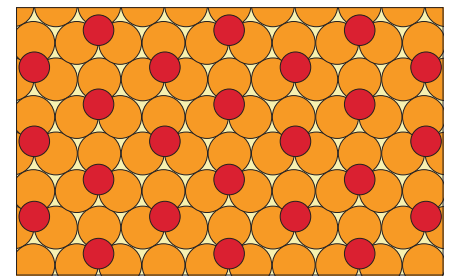

(111)

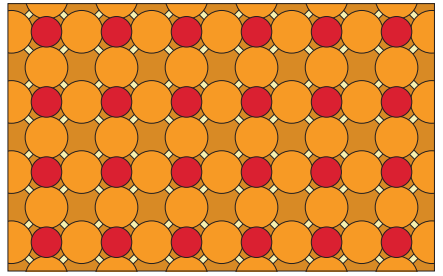

(100)

\section{c}

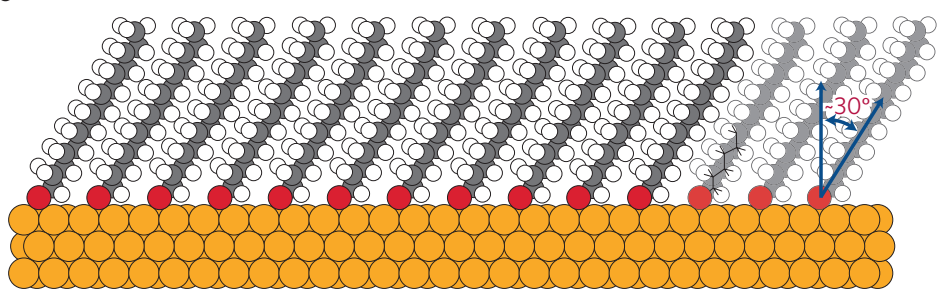

$\mathrm{Au}$ 